\title{
Políticas para a (não) manutenção da língua alemã em Marechal Cândido Rondon
}

\author{
Políticas para la (no) manutención de la lengua alemana en Marechal \\ Cândido Rondon
}

\author{
Policies for (non) maintenance of the German language in Marechal Cândido \\ Rondon
}

\author{
Franciele Maria Martiny ${ }^{1}$
}

\begin{abstract}
Resumo
Neste trabalho serão abordadas discussões em torno das políticas linguísticas e educacionais que envolvem o ensino e aprendizagem da língua alemã no município de Marechal Cândido Rondon (PR) a partir da implantação do CELEM e do curso universitário de licenciatura de Letras Português/Alemão. A abordagem teórica está amparada na Sociolinguística com atenção voltada a contextos de minorias linguísticas, a partir de análises interpretativistas advindas da Tese de Doutoramento defendida em 2015. Como conclusão, tem-se que, apesar das inciativas supracitadas, para tentativa de manutenção da língua de imigração da comunidade, contatou-se a falta de adequação das propostas para um ensino culturalmente sensível, o que tem ocasionado salas de aulas esvaziadas, evidenciando também que os falantes estão deixando de aprender e ensinar alemão tanto em contextos formais (nos cursos existentes) quanto em contextos informais (em seus lares e na comunidade).
\end{abstract}

Palavras-Chave: Língua alemã; Marechal Cândido Rondo; Políticas linguísticas e educacionais.

\section{Resumen}

En este trabajo serán abordadas discusiones sobre las políticas lingüísticas y educacionales que involucran la enseñanza y aprendizaje de la lengua alemana en Marechal Cândido Rondon (PR) a partir de la implementación del CELEM y del curso universitario de licenciatura de Letras Portugués/Alemán. El abordaje teórico está amparado en la Sociolingüística con atención a contextos de minorías lingüísticas, a partir de análisis interpretativitas advenidas de la Tesis de Doctoramiento defendida en 2015. Como conclusión, a pesar de las iniciativas supra citadas, para la tentativa de manutención de la lengua de inmigración de la comunidad, se constató la falta de adecuación de las propuestas para la enseñanza culturalmente sensible, lo que implica en aulas vacías, evidenciando también que los hablantes están dejando de aprender y enseñar alemán tanto en contextos formales (en los cursos existentes) cuanto en contextos informales (en sus casas y en la comunidad).

Palabras claves: Lengua Alemana, Marechal Cândido Rondon, Políticas lingüísticas y educacionales.

\begin{abstract}
This paper will discuss linguistic and educational policies that involve teaching and learning of German language in the municipality of Marechal Cândido Rondon (PR), starting with the implementation of CELEM and of the Portuguese/German undergraduate course. The theoretical approach is supported by Sociolinguistics with attention focused on contexts of linguistic minorities, based on interpretative analyzes coming from the Doctoral Thesis defended in 2015. In conclusion, despite the above-mentioned initiatives, attempts to maintain the community's immigration language have been linked to the lack of appropriateness of the proposals for culturally sensitive teaching, which has led to empty classrooms. It allows to conclude that speakers are failing

\footnotetext{
${ }^{1}$ Doutora em Letras pela Universidade Estadual do Oeste do Paraná (UNIOESTE); Docente na área de Letras e do Ciclo Comum de Estudos da Universidade Federal da Integração Latino-Americana (UNILA); Foz do Iguaçu, Paraná, Brasil; franciele.martiny@unila.edu.br. Trabalho apresentado no I Seminário Latino-Americano de Estudos em Cultura - SEMLACult, Foz do Iguaçu/PR, Brasil, 2017.
} 
to learn and teach German both in formal contexts (in existing courses) and in informal contexts (in their homes and in the community).

Keywords: German language; Marechal Cândido Rondon; Linguistic and educational policies.

\section{Introdução}

No Brasil, as políticas e planificações linguísticas estão centralizadas, em sua maior parte, à soberania do Estado por meio das secretarias estaduais de Educação e do Ministério da Educação. Por conseguinte, o direcionamento do currículo escolar e demais regulamentações partem dos Governos Federal, Estadual e Municipal, assim como as disciplinas que são obrigatórias ou que podem ser integradas ao sistema escolar de ensino.

Basicamente, as leis e os percursos metodológicos que regulam o ensino de línguas nas escolas brasileiras estão centralizados em três documentos oficiais: nas Leis de Diretrizes e Bases da Educação (LDB), de 1996, nos Parâmetros Curriculares Nacionais (PCNs), de 1998, e nas diretrizes específicas de cada Estado, no caso do Paraná, pelas Diretrizes Curriculares para o Estado do Paraná (DCEs), de 2008.

Os documentos supracitados compreendem o ensino da língua materna como responsabilidade da escola, sendo ele o ensino da língua portuguesa, língua oficial brasileira. A partir dessa constatação, verifica-se que os documentos de ensino privilegiam somente uma língua e, por conseguinte, a visão de um país, ainda, monolíngue. Situação que evidencia o espaço minorizado de outras línguas presentes no país, como seriam, por exemplo, as línguas de imigração.

Embora sejam mencionadas as línguas de imigrantes, de indígenas e de sinais nos documentos oficiais se observa muito latente essa centralização no ensino de uma única língua, como uma maneira de demarcação de uma identidade nacional, uma idealização arraigada há muitas décadas no país. Tal problemática é recorrente no sistema escolar como um todo e, inclusive, em regiões de imigração, essa situação fica bem marcada, pois não há uma política linguística adequada a tais situações, de maneira mais esclarecedora. Tal fato desencadeia muitas dúvidas sobre como desenvolver uma educação intercultural de línguas que seja libertadora e não engessada, limitada.

Nesse sentido, entende-se que não haver uma política apropriada já é uma política, mesmo que não material, não palpável, sendo que seus desdobramentos podem interferir diretamente na manutenção e preservação das línguas, como seria o que está acontecendo no município de Marechal Cândido Rondon, Paraná, onde não há (e nunca houve ao longo da histórica do município) políticas voltadas ao ensino de língua alemã nas escolas municipais, o 
que afeta também a continuidade e preservação dessa língua, entre outros fatores que serão discutidos na sequência. Por outro lado, há duas inciativas existentes na localidade, por intermédio do Governo Estadual, a implantação do ensino de língua alemã no curso de licenciatura em uma universidade pública em Letras Português/Alemão (iniciado em 2003), e no ensino extracurricular, no CELEM (iniciado em 1998). Tratam-se de tentativas de manutenção da língua na comunidade, mas que não estão conseguido alcançar esse objetivo, tendo as salas de aula um número reduzido de alunos e problemas com falta de docentes e com mercado de trabalho futuro, como no próprio caso da licenciatura, o que dificulta até mesmo a realização de estágio supervisionado (MARTINY, 2015).

A situação do município rondonense retoma os estudos de Calvet (2007) sobre as intervenções por meio de políticas linguísticas, em contextos sociolinguísticos complexos, que podem ocasionar problemas ao serem passadas para o domínio do planejamento linguístico, ou seja, com sua implantação. Diante dessa breve contextualização, na sequência deste texto, serão debatidos aspectos relacionados ao ensino e transmissão de língua alemã, com discussões pautadas na Sociolinguística, dentro da Linguística Aplicada, voltada à línguas minoritárias por meio de dados levantados em Tese de Doutoramento, em 2015, a partir de entrevistas e de análise documental.

\section{Políticas para o (não) ensino de língua alemã na comunidade rondonense}

Como já citado na introdução deste texto, o que fica latente, de um modo geral, é que o ensino do português, no Brasil, por muito tempo, assumiu um papel cívico de abrasileiramento dos diversos falantes de línguas de imigração. Nesse sentido, as línguas minoritárias registraram perdas na medida em que diminuíram suas funções, até que essas não sejam mais adquiridas pelas novas gerações e sejam esquecidas.

Oliveira (2009) mostra muito bem a necessidade de reflexão constante sobre a pluralidade linguística do Brasil, sem esquecer o percurso histórico da língua no país:

Muito mais interessante seria redefinir o conceito de nacionalidade, tornando-o plural e aberto à diversidade: seria mais democrático e culturalmente mais enriquecedor, menos violento e discricionário, e permitiria que conseguíssemos nos relacionar de uma forma mais honesta com a nossa própria história: nem tentando camuflar e maquilar o passado, escondendo os horrores das guerras, dos massacres e da escravidão que nos constituíram, nem vendo a história apenas como uma sequiência de denúncias a serem feitas (OLIVEIRA, 2009, p. 7). 
Coaduna-se com o referido teórico para quem há um fator político-ideológico que envolve o ensino de línguas nas escolas para além da questão pedagógica. A perspectiva volta-se mais para o status hegemônico que certas línguas ocupam, ao invés de oferecer um espaço legítimo de diversidade linguística e cultural para as línguas de imigração na escola. Nesse sentido, verifica-se a importância de um alargamento na definição de nacional a fim de ser plural, o que se acredita estar longe de ser efetivado no país.

Por este viés, considera-se que não adianta apenas 'reconhecer' a pluralidade e abrir a possibilidade à escola de fazer a inclusão de certas línguas, é necessário em um âmbito, muito maior, desencadear uma série de ações políticas em torno dessas questões, pois da maneira como os textos educacionais apropriam-se da temática, ela se torna simplista e superficial, ratificando ainda mais o afastamento, entre as questões linguísticas, socioculturais e históricas presentes na realidade brasileira, nas diversas comunidades. O resultado é uma série de políticas educacionais simplórias que não observam a complexidade das relações sociais do país e as especificidades de cada local. A partir dessa discussão, Savedra (2003) menciona a necessidade da definição de uma política linguística brasileira que abranja as situações de bilinguismo, decorrentes de movimentos migratórios, bem como de situações de fronteira.

Acredita-se, portanto, que faltam às línguas de imigração voz e visibilidade para serem incluídas nos diálogos sobre políticas linguísticas para uma Educação de Língua(s), culturalmente sensível, ampliando discussões em torno dos conceitos de bilinguismo, diglossia, mudança de código, alternância de código e empréstimos, face às diferenças encontradas ao longo da convivência do português com as línguas minoritárias e sua inclusão no ensino. Estas importantes questões são, muitas vezes, negligenciadas pela sociedade e pelos próprios educadores da língua. Além da citada invisibilidade, um estigma muito grande, na maioria das vezes, acompanha os falantes bilíngues dessas comunidades, uma vez que seu falar é considerado inferiorizado em relação aos falares de prestígio e considerados majoritários no país. Falta, nesse sentido, uma consciência sociolinguística maior na sociedade e respeito aos sujeitos inseridos nessas localidades.

É mister ressaltar que a região em que o município rondonense situa-se é considerada sociolinguisticamente complexa (VON BORSTEL, 1999; PEREIRA, 1999). Isso se deve, conforme as autoras supracitadas, a alguns fatores, como: a) as línguas de fronteiras; b) a localização próxima às áreas de tríplice fronteira entre Brasil/Argentina/Paraguai; c) a presença de línguas indígenas nas pequenas comunidades indígenas em alguns municípios da região e d) a presença de línguas de imigrações de italianos, alemães, poloneses, ucranianos e outras culturas étnicas na região. Enfatiza-se que localidade estudada foi colonizada, na 
década de 1950, em sua grande maioria, por imigrantes alemães e seus descendentes vindos de regiões germânicas da Europa, do Rio Grande do Sul e de Santa Catarina, por intermédio de um Plano de Ação da Colonizadora Maripá que possuía uma série de regras, entre elas a escolha dos elementos humanos para povoar a região.

Sobre o falar desses imigrantes alemães e seus descendentes, que povoaram a região, constata-se que há a influência de elementos da variedade padrão do alemão e dos vários dialetos: suábio, francônio, pomerano, vestfaliano, Deutschruss com o português padrão e suas variedades (VON BORSTEL, 1999), causando uma mescla ou hibridização linguística que, de maneira geral, é vista pela comunidade como algo negativo, que deveria ser evitado e vários entrevistados destacaram que é o que tem acontecido, muitas vezes, os pais não querem que seus filhos falem “errado”, ou seja, que sejam estigmatizados (MARTINY, 2015).

A respeito disso, considera-se que essas questões em torno de atitudes associadas às línguas são importantes para serem discutidas no ensino formal e dentro da própria comunidade linguística, uma vez que

[...] boa parte do êxito da aplicação de medidas de política lingüística que promovam os direitos lingüísticos das minorias bilíngües depende da compreensão do que efetivamente possa motivar as micro-decisões de cunho político empreendidas pelos membros das comunidades, e que compreendem valores, ideologias, mitos, "ressentimentos", concepções e preconceitos lingüísticos presentes na interação diária entre os grupos sociais e os falantes das diversas línguas e variedades em contato. Por exemplo, o currículo da escola, o tipo de material didático utilizado e as práticas didáticas do professor refletem de certo modo a visão desses aspectos (ALTENHOFEN, 2004, p. 86).

A partir desse posicionamento, compreende-se que é necessário que as instâncias menores que o Estado (escolas, igrejas, famílias e administração local) discutam as políticas linguísticas promovidas pelo governo ou mesmo as não promovidas, a fim de distribuir as tendências mais gerais, combatendo o preconceito em torno das línguas. Até porque, na maior parte das vezes, é no âmbito familiar que se decide a perpetuação da língua de imigração, trata-se, assim, de um planejamento consciente.

É o que tem acontecido com a língua alemã no município de Marechal Cândido Rondon, que é uma língua de imigração, mas a procura da comunidade pelo ensino formal é insatisfatória, ocasionando o esvaziamento das salas ao longo dos cursos que ofertam a língua de cultura étnica. Até porque, contatou-se que as línguas de imigrantes são ensinadas de semelhante maneira às demais línguas estrangeiras, ou seja, não há um tratamento diferenciado por uma abordagem cultural e histórica local. 
Nesse contexto, os cursos que formam professores para atuar nas diferentes áreas do Ensino Fundamental e Médio, não focalizam, ou focalizam muito pouco, em seus projetos políticos pedagógicos, discussões necessárias à multiplicidade de línguas e hibridizações linguísticas, tampouco observam as implicações para o letramento. Esse cenário pode gerar despreparo do professor de línguas frente à sala de aula diante os vários desafios, exemplo das línguas em contato.

A referida situação é ressaltada por Spinassé (2009) sobre as aulas na língua alemã que são trabalhadas da mesma forma nos distintos contextos, sem levar em consideração as especificidades de cada local. Portanto, o que se tem é o ensino de alemão padrão da mesma maneira, sem a observação tão importante das peculiaridades de cada local, ou seja, não há, geralmente, uma reflexão didática sobre o ensino de língua alemã como LE, visando, por exemplo, em como aproveitar a variedade linguística já conhecida do aluno, sua experiência e contato anterior com a língua e com a cultura germânica.

Situação semelhante foi encontrada no município rondonense. Pelos relatos dos entrevistados, observou-se que os falantes acreditavam não serem bilíngues (português/alemão) porque não falam “o alemão de verdade", ou "o alemão da Alemanha" ou "o alemão correto". Nesses casos, muitas vezes, as pessoas preferem deixar de falar e ensinar a língua devido a essa crença. De acordo com Fritzen (2008), essa situação dos "deslocados" se torna ainda mais grave e complexa quando constatamos que os grupos descendentes de imigrantes sofrem duplo preconceito. Quando falam alemão, falam um alemão corrompido, que "não é mais alemão", e precisam se desculpar por isso; quando falam português, as marcas do alemão denunciam sua origem social e étnica: "são colonos alemães" (p. 349).

Nesse cenário, a iniciativa da implantação da língua alemã pelo CELEM e pela Univeridade, de maneira geral, não tem resgatado a cultura, a língua dos descendentes, pois há um estranhamento entre os alunos e a referida língua, uma vez que não se identificam com ela em sala de aula. Isso porque, a maior parte do tempo, o ensino fica baseado na modalidade padrão que se distancia da língua conhecida e aprendida no âmbito familiar. Além disso, pouco se usa do que o aluno já traz de conhecimento linguístico e cultural.

\section{Conclusões}

A partir das considerações feitas ao longo deste trabalho, verifica-se que duas situações corroboram o apagamento gradual das línguas de imigração no município rondonense. Primeiro, as políticas linguísticas não conseguem considerar a realidade 
plurilíngue do país e, segundo, os próprios imigrantes que optam em deixar de usar a sua língua familiar ou de entorno por escolha ou pelo contexto. Essas questões influenciam diretamente no insucesso do ensino dessas línguas.

Considera-se que é urgente haver uma mudança cultural e linguística com relação à língua de imigração, no município, ou seja, é necessário que o bilinguismo seja aceito e valorizado na comunidade, descontruído estereótipos e estigmas ainda muito presentes na comunidade. Assim, seria possível fortalecer as línguas dos grupos teuto-brasileiros por meio de uma educação plurilíngue, na qual as variantes do português e os vários dialetos da língua alemã fossem tratados com respeito na constituição social, histórica e identitária dos indivíduos brasileiros.

Defende-se que é preciso haver um trabalho intenso em torno das questões culturais da localidade, para que as políticas em torno das línguas passem a funcionar como catalisadoras de forças para a manutenção do bilinguismo, minimizando o conflito diglóssico por meio do redimensionamento do valor simbólico da língua minorizada em relação à língua dominante.

\section{Referências}

ALTENHOFEN, Cleo. Política lingüística, mitos e concepções lingüísticas em áreas bilíngües de imigrantes (alemães) no Sul do Brasil. Revista Ibero Americana. 2004. Disponível em: <http://www.ibero- americana.net/files/ejemplo_por.pdf>. Acesso em: 15 jan. 2012.

BRASIL. Parâmetros Curriculares Nacionais: terceiro e quarto ciclos do Ensino Fundamental - Língua Portuguesa. Brasília: MEC/SEF, 1998a. Disponível em: <http://portal.mec.gov.br/seb/arquivos/pdf/portugues.pdf>. Acesso em: 15 jan. 2012.

Parâmetros Curriculares Nacionais: terceiro e quarto ciclos do Ensino Fundamental - Língua Estrangeira. Brasília: MEC/SEF, 1998b. Disponível em: <http://portal.mec.gov.br/seb/arquivos/pdf/pcn_estrangeira.pdf>. Acesso em: 15 jan. de 2012.

Brasília: 1996.

. Senado Federal. Lei de Diretrizes e Bases da Educação Nacional: nº 9394/96.

CALVET, Louis-Jean. As políticas lingüísticas. Tradução de Isabel de Oliveira Duarte, Jonas Tenfen e Marcos Bagno. São Paulo: Parábola, 2007.

FRITZEN, Maristela P. "Ich spreche anders, aber das ist auch deutsch": línguas em conflito em uma escola rural localizada em zona de imigração no sul do Brasil. Trab. Ling. Aplic., Campinas, v. 47, n.2, p. 341-356, Jul./Dez. 2008.

MARTINY, Franciele M. Políticas linguísticas e educacionais: o ensino de língua alemã em Marechal Cândido Rondon, Paraná. 2015. 317 f. Tese (Doutorado em Letras) - Programa de PósGraduação em Letras, Universidade Estadual do Oeste do Paraná - UNIOESTE, Cascavel, 2015. 
OLIVEIRA, Gilvan, M. Brasileiro fala português: Monolinguismo e Preconceito Linguístico. Revista Linguasagem, 11. Ed., novembro e dezembro de 2009. Disponível: $\langle$ http://www.letras.ufscar.br/linguasagem/edicao11/artigo12.pdf $>$. Acesso em: 10 jul. de 2012.

PARANÁ. Diretrizes Curriculares de Língua Portuguesa para os anos finais do Ensino Fundamental e Ensino Médio. Superintendência da Educação. Curitiba: SEED/SE, 2008a. Disponível em: <http://www.diaadiaeducacao.pr.gov.br/diaadia/diadia/arquivos/File/livro_e_diretrizes/diretri zes/diretrizeslinguaportuguesa72008.pdf>. Acesso em: 15 mai. de 2010.

PEREIRA, Maria C. Naquela comunidade rural, os adultos falam "alemão" e "brasileiro". $\mathrm{Na}$ escola, as crianças aprendem o português: um estudo do continuum oral/escrito em crianças de uma classe bisseriada. Campinas, 1999. Tese (Doutorado em Linguística Aplicada). IEL/Unicamp, Campinas - SP, 1999. Disponível em: <www.bibliotecadigital.unicamp.br > Bases Disponíveis >. Acesso em: 10 jan. de 2013.

SAVEDRA, Mônica M. G. Política linguística no Brasil e no Mercosul: o ensino de primeiras e segundas línguas em um bloco regional. Revista Palavra PUC/Rio. Volume Temático: Línguas em contato, n.11. Rio de Janeiro: Editora Trarepa, 2003, p. 39-54.

SPINASSÉ, Karen Pupp. Duas faces do ensino do alemão como língua estrangeira no Brasil. In: MAURÍCIO, Lúcia Velloso. (Org.). Ensino e aprendizagem de línguas estrangeiras: o foco na integração. Em aberto. v. 22, n.81, Brasília: O Instituto, agosto de 2009, p. 61-80.

VON BORSTEL, Clarice, N. Contato lingüístico e variação em duas comunidades bilíngües do Paraná. Rio de Janeiro, 1999. Tese (Doutorado em Linguística). Curso de Pós-Graduação em Letras Universidade Federal do Rio de Janeiro: Rio de Janeiro - RJ, 1999. 